\title{
FAKTOR PENYEBAB MEDICATION ERROR PADA PELAYANAN KEFARMASIAN RAWAT INAP BANGSAL ANAK RSUD TOBELO
}

\author{
Steyfan Benawan $^{1)}$, Gayatri Citraningtyas ${ }^{1)}$, Weny I. Wiyono ${ }^{1)}$ \\ ${ }^{1)}$ Program Studi Farmasi FMIPA UNSRAT Manado, 95115
}

\begin{abstract}
The incidence of Medication Error (ME) is found to be quite high in prescribing pediatric patients. The high problem of ME in pediatric patients shows the need for concrete action to reduce the incidence so the incident that harm pediatric patients can be avoided. The purpose of the research is to know the causes of ME in the prescribing and dispensing phase. This research using descriptive study with prospective data collection techniques. This result showed that causative factors of the ME prescribing phase work disturbances which were disturbed by telephone ringing, include workloads that are health workers unable to solve themselves every job, communication such as lack of good oral communication of doctors and pharmacist about drug use for patients, environmental conditions that were lighting that were less supportive at work, and education namely prescription writing that does not meet the prescription completeness requirements. Factors that cause ME dispensing work disturbances which were disturbed by telephone ringing, communication that is lacking in communication between pharmacist and nurses in preparing patient medication, include workloads that are health workers unable to solve themselves every job, environmental conditions namely the absence of drug preparation, and education rooms preparations of drugs that are not according to the prescription.
\end{abstract}

Keywords: Medication error, hospitalization, pediatric ward.

\begin{abstract}
ABSTRAK
Kejadian Medication Error (ME) ditemukan cukup tinggi pada resep pasien anak. Tingginya permasalahan ME pada pasien anak menunjukan perlunya tindakan nyata untuk mengurangi kejadian tersebut agar dapat dihindari hal-hal yang merugikan bagi pasien anak. Tujuan penelitian yaitu mengetahui faktor penyebab ME pada fase prescribing dan dispensing. Penelitian ini merupakan penelitian deskriptif dengan teknik pengambilan data secara prospektif. Hasil penelitian menunjukkan bahwa faktor penyebab ME fase prescribing meliputi gangguan bekerja yaitu terganggu dengan dering telepon, beban kerja yaitu tenaga kesehatan tidak mampu mengerjakan sendiri setiap pekerjaan, komunikasi yaitu kurang baiknya komunikasi lisan dokter dan apoteker tentang penggunaan obat untuk pasien, kondisi lingkungan yaitu pencahayaan yang kurang mendukung saat bekerja, dan edukasi yaitu penulisan resep yang tidak memenuhi syarat kelengkapan resep. Faktor penyebab ME fase dispensing meliputi gangguan bekerja yaitu terganggu dengan dering telepon, komunikasi yaitu kurang baiknya komunikasi apoteker dan perawat dalam penyiapan obat pasien, beban kerja yaitu tenaga kesehatan tidak mampu menyelesaikan sendiri setiap pekerjaan, kondisi lingkungan yaitu tidak adanya ruangan penyiapan obat, dan edukasi yaitu penyiapan obat yang tidak sesuai permintaan resep.
\end{abstract}

Kata Kunci: Medication error, rawat inap, bangsal anak. 


\section{PENDAHULUAN}

Pelayanan kefarmasian merupakan bertanggungjawab kepada pasien yang berkaitan dengan sediaan farmasi dengan maksud mencapai hasil yang pasti untuk meningkatkan mutu kehidupan pasien. Salah satu tujuan pelayanan kefarmasian yaitu melindungi pasien dan masyarakat dari penggunaan obat yang tidak rasional dalam rangka keselamatan pasien (patient safety) (Depkes RI, 2014). Keselamatan pasien sebagai suatu upaya untuk mencegah terjadinya bahaya atau cedera pada pasien selama proses pengobatan.

Medication Error (ME) adalah suatu kegagalan dalam proses pengobatan yang memiliki potensi membahayakan pada pasien dalam proses pengobatan ataupun perawatannya (Aronson, 2009). Laporan Institut Of Medicine (IOM) terkait dengan kejadian ME, yaitu sekitar 3,7\% pasien dari pendaftaran tercemar oleh kasus kesalahan pemberian obat karena efek samping obat yang menyebabkan pasien cacat dan seperempatnya karena kasus kelalaian. Laporan dari IOM menemukan bahwa 44.000 dari 98.000 pasien meninggal di rumah sakit sekunder Amerika Serikat (AS) karena adanya kesalahan pemberian. Selain dampak pada pasien, rumah sakit juga mengalami kerugian yaitu secara finansial, reputasi, dan image (Nasution, 2009).

Kejadian ME ditemukan cukup tinggi pada resep pasien anak. Tingginya permasalahan ME pada pasien anak menunjukan perlunya tindakan nyata untuk mengurangi kejadian tersebut agar dapat dihindari hal-hal yang merugikan bagi pasien anak (Maiz et al., 2014). Ketidaklengkapan dan ketidakjelasan penulisan resep merupakan bentuk ME pada fase prescribing yang dapat merugikan bagi pasien anak. Untuk menurunkan resiko, penting untuk memahami apa yang menyebabkan ME.

Tujuan penelitian untuk mengetahui faktor yang dapat menyebabkan Medication Error pada fase prescribing dan dispensing di rawat inap bangsal anak RSUD Tobelo.

\section{METODOLOGI PENELITIAN}

Penelitian ini dilakukan di rawat inap bangsal anak dan instalasi farmasi RSUD Tobelo pada bulan Oktober 2018 - Februari 2019. Jenis penelitian deskriptif dengan pengambilan data secara prospektif. Populasi dalam penelitian ini yaitu seluruh tenaga kesehatan yang terlibat dalam pelayanan kefarmasian di rawat inap bangsal anak dan instalasi farmasi RSUD Tobelo. Sampel penelitian ini diambil dengan menggunakan metode total sampling yaitu seluruh populasi dalam penelitian dijadikan sebagai subjek penelitian. Pengumpulan data berupa data primer dan data sekunder. Data primer didapat peneliti secara langsung melalui pengumpulan data lapangan dalam bentuk kuesioner yang diadaptasi dari Donsu (2016) dan wawancara. Sedangkan data sekunder diperoleh peneliti dari sumber yang sudah ada berupa studi kepustakaan.

Analisis data yang digunakan dalam penelitian ini adalah analisis univariat dimana data akan ditampilkan atau disajikan dalam bentuk tabel frekuensi dan persentase. Peneliti menganalisa data dengan menetapkan kriteria penilaian. Penilaian menggunakan skala Likert dengan cara menetapkan bobot jawaban terhadap tiap item yaitu skor pernyataan dengan pilihan Sangat Setuju (SS) bernilai 4, Setuju (S) bernilai 3, Kurang Setuju (KS) bernilai 2 dan Tidak Setuju (TS) bernilai 1. Tiap item pernyataan dijumlahkan bobot 
jawaban sehingga didapatkan total skor pada masing-masing pernyataan. Skor terendah untuk tiap pernyataan pada masing-masing faktor penyebab dipilih dan selanjutnya dideskripsikan sebagai faktor-faktor penyebab ME fase prescribing dan dispensing pada pelayanan kefarmasian bangsal anak RSUD Tobelo.

\section{HASIL DAN PEMBAHASAN}

Faktor Penyebab Medication Error pada Fase Prescribing

Tabel 1. Karakteristik Responden

\begin{tabular}{lccc}
\hline NO. & Karakteristik & $\begin{array}{c}\text { Freku } \\
\text { ensi }\end{array}$ & $\begin{array}{c}\text { Persenta } \\
\text { se (\%) }\end{array}$ \\
\hline 1. & Umur & & \\
& $20-30$ tahun & 13 & 62 \\
& $31-40$ tahun & 8 & 38 \\
& $41-50$ tahun & 0 & 0 \\
& $51-60$ tahun & 0 & 0 \\
& $>60$ tahun & 0 & 0 \\
\hline & Total & 21 & 100 \\
\hline 2. & Jenis Kelamin & & \\
& Perempuan & 17 & 81 \\
& Laki-laki & 4 & 19 \\
\hline & Total & 21 & 100 \\
\hline Pendingan & &
\end{tabular}

3. Pendidikan

D3/Sederajat 29

S1

33

S1 Profesi

33

S2

\begin{tabular}{ccc} 
S2 & 1 & 5 \\
\hline Total & 21 & 100 \\
\hline
\end{tabular}

4. Pekerjaan

Dokter Umum

Dokter

Spesialis Anak

Apoteker

Tenaga Teknis

Kefarmasian

4

9

2

5

24

10

\begin{tabular}{lll} 
Kefarmasian & & 48 \\
\hline Total & 21 & 100 \\
\hline
\end{tabular}

5. Lama Kerja

$1-5$ tahun

14

$6-10$ tahun
67

33

\begin{tabular}{ccc}
$>10$ tahun & 0 & 0 \\
\hline Total & 21 & 100 \\
\hline
\end{tabular}

Berdasarkan hasil yang didapat pada Tabel 1, diketahui bahwa mayoritas umur responden adalah 20-30 tahun sebanyak 13 responden (62\%), dengan mayoritas jenis kelamin responden adalah perempuan sebanyak 17 responden (81\%), dengan mayoritas pendidikan S1 dan S1 Profesi masing-masing sebanyak 7 responden (33\%), dengan mayoritas pekerjaan tenaga teknis kefarmasian sebanyak 10 responden $(48 \%)$ dan lama bekerja terbanyak 1-5 tahun sebanyak 14 responden $(67 \%)$.

Tabel 2. Faktor Penyebab Prescribing Error

\begin{tabular}{llcc}
\hline $\begin{array}{l}\text { Faktor } \\
\text { Penyebab }\end{array}$ & \multicolumn{1}{c}{ Pernyataan } & N & \% \\
\hline Komunikasi & Komunikasi lisan & & \\
& dokter dan apoteker & & \\
& tentang penggunaan & & \\
& obat untuk pasien & & \\
& berlangsung baik & & \\
& a. Sangat Setuju & 7 & 33 \\
& b. Setuju & 8 & 38 \\
& c. Kurang Setuju & 6 & 29 \\
& d. Tidak Setuju & 0 & 0 \\
\hline
\end{tabular}

\begin{tabular}{ll}
\hline Kondisi & Pencahayaan area \\
Lingkungan & kerja mendukung \\
& dalam pelaksanaan \\
& tugas tenaga \\
& kesehatan
\end{tabular}

a. Sangat Setuju 733

b. Setuju 9943

\begin{tabular}{lll} 
c. Kurang Setuju & 5 & 24 \\
\hline
\end{tabular}

$\begin{array}{lll}\text { d. Tidak Setuju } & 0 & 0\end{array}$

Gangguan/ Tenaga kesehatan

interupsi merasa tidak

bekerja terganggu dengan dering telepon yang bunyi tiba-tiba
a. Sangat Setuju
$\begin{array}{ll}2 & 10\end{array}$
b. Setuju
$\begin{array}{ll}4 & 19\end{array}$
c. Kurang Setuju
$11 \quad 52$ 


\begin{tabular}{llcc}
\hline & d. Tidak Setuju & 4 & 19 \\
\hline Beban & Tenaga kesehatan & & \\
kerja & mampu & & \\
& menyelesaikan sendiri & & \\
& setiap pekerjaan & & \\
a. Sangat Setuju & 6 & 29 \\
& b. Setuju & 8 & 38 \\
& c. Kurang Setuju & 2 & 9 \\
& d. Tidak Setuju & 5 & 24 \\
\hline Edukasi & Penulisan resep & & \\
& memenuhi syarat & & \\
& kelengkapan resep & & \\
& a. Sangat Setuju & 9 & 43 \\
& b. Setuju & 7 & 33 \\
& c. Kurang Setuju & 5 & 24 \\
& d. Tidak Setuju & 0 & 0 \\
\hline
\end{tabular}

Berdasarkan hasil faktor penyebab Medication Error (ME) fase prescribing pada Tabel 2 menunjukkan responden dalam penelitian ini mempersepsikan faktor gangguan/interupsi bekerja dapat menyebabkan ME terutama dengan dering telepon yang bunyi tiba-tiba karena sebanyak $19 \%$ responden menyatakan tidak setuju dengan pernyataan tenaga kesehatan tidak terganggu dengan dering telepon yang bunyi tiba-tiba. Gangguan lingkungan yang tidak nyaman seperti berisik, suasana kerja yang tidak harmonis, gangguan telepon, kelebihan beban kerja karena Sumber Daya Manusia (SDM) kurang, merupakan sumber stress bagi para petugas. Kondisi yang demikian dapat mengganggu konsentrasi dan perhatian dari para petugas sehingga kesalahan dapat terjadi (Cahyono dan Suharjo, 2008).

Responden mempersepsikan faktor beban kerja dapat menyebabkan ME pada fase prescribing terutama untuk pernyataan tenaga kesehatan mampu menyelesaikan sendiri setiap pekerjaan dinyatakan tidak setuju oleh $24 \%$ responden. Beban kerja adalah jumlah unit kerja yang ditugaskan pada satu sumber daya dalam periode waktu tertentu (Mansouri et al.,
2014). Dalam proses penulisan resep dokter harus membagi waktu antara menulis resep pasien, visite pasien, menulis status pasien, buku pegangan dokter dan catatan untuk dokter jaga. Menurut Hartayu dan Widayati (2005) tingginya tingkat kesibukan dokter sehubungan dengan banyaknya pasien dapat menyebabkan kesalahan dalam penulisan resep obat. Apabila jumlah pasien sedikit, tugas dan pekerjaan dari tenaga kesehatan dapat dikontrol dengan baik, namun jika jumlah pasien banyak dengan kurangnya SDM yang tersedia dapat menyebabkan bertambahnya jam beban kerja atau tidak terlaksana dan tidak maksimal pekerjaan yang lain. Beban kerja yang berlebihan akan mengurangi kualitas pelayanan akan tetapi sebaliknya beban kerja yang sesuai dengan porsinya dapat meningkatkan kualitas melalui pengembangan inovasi pelayanan (Ilyas, 2011).

Responden mempersepsikan faktor komunikasi dapat menyebabkan ME terutama sebanyak 29\% responden menyatakan kurang setuju dengan komunikasi lisan dokter dan apoteker tentang penggunaan obat berlangsung baik. Komunikasi yang baik antara dokter dengan tenaga farmasi sebenarnya memiliki banyak manfaat yang dapat diperoleh terutama dalam hal keamanan dan keselamatan (pengobatan) pasien. Namun dalam praktek sehari-hari di rumah sakit, jalur untuk membina komunikasi ini sangatlah minim atau tidak ada sama sekali. Komunikasi informal (misalnya melalui telepon) sering kali waktunya tidak tepat, saat dokter menerima telepon belum tentu dokter tersebut langsung dapat mengingat pasien yang sedang dibicarakan. Jika seorang tenaga farmasi harus menyampaikan pesan temannya yang kebetulan sudah lewat waktu tugasnya namun belum sempat berkomunikasi dengan dokter yang menangani pasien, maka 
belum tentu tenaga farmasi tersebut memahami keadaan klinis pasien sehingga hasil akhir pembicaraan/konsultasi tidak optimal (Soejono, 2008).

Adapun kondisi lingkungan saat proses peresepan dinyatakan kurang setuju terutama terhadap pencahayaan area kerja mendukung dalam pelaksanaan tugas tenaga kesehatan. Faktor pencahayaan merupakan salah satu faktor lingkungan kerja yang termasuk kelompok faktor resiko, jika intensitas pencahayaan tidak memadai maka dapat menyebabkan produktivitas tenaga kerja menurun. Pencahayaan juga berpengaruh terhadap kesehatan mata dan secara tidak langsung mempengaruhi tingkat konsentrasi terhadap pekerjaan. Kondisi pencahayaan tempat kerja yang redup umumnya menyebabkan tenaga kerja berupaya untuk dapat melihat pekerjaan dengan sebaik-baiknya dengan cara melihat secara terus menerus, sehingga dapat menimbulkan kelelahan mata, kelelahan mental, konsentrasi dan kecepatan berpikir menurun demikian juga kemampuan intelektualnya juga mengalami penurunan. Pencahayaan yang kurang dapat mengganggu pelayanan kesehatan di rumah sakit dan lebih jauh dapat menimbulkan gangguan terhadap kesehatan (Tarwaka dan Lilik, 2004).

Hasil jawaban kuesioner terhadap edukasi sebanyak $24 \%$ responden menyatakan kurang setuju penulisan resep memenuhi syarat kelengkapan resep. Masalah prescribing error yang terjadi di RSUD Tobelo adalah kesalahan prosedural dan administratif berupa tulisan resep yang tidak terbaca dan masalah kelengkapan resep. Beberapa jenis kesalahan memang cukup banyak dijumpai dalam penulisan resep misalnya: masih banyak resep obat yang ditulis tanpa ada signa atau aturan pakai, kadangkala signa yang dituliskan kurang jelas atau kurang lengkap. Hal ini terutama banyak terdapat pada resep-resep yang ditulis oleh dokter yang berpraktek di rumah sakit. Sebagai akibatnya, dapat menghambat proses pengobatan pasien.

Faktor Penyebab Medication Error pada Fase Dispensing

Tabel 3. Karakteristik Responden

\begin{tabular}{|c|c|c|c|}
\hline $\begin{array}{l}\text { NO } \\
.\end{array}$ & Karakteristik & $\begin{array}{c}\text { Freku } \\
\text { ensi }\end{array}$ & $\begin{array}{c}\text { Persenta } \\
\text { se }(\%)\end{array}$ \\
\hline \multirow[t]{7}{*}{1.} & Umur & & \\
\hline & $20-30$ tahun & 22 & 69 \\
\hline & $31-40$ tahun & 10 & 31 \\
\hline & $41-50$ tahun & 0 & 0 \\
\hline & $51-60$ tahun & 0 & 0 \\
\hline & $>60$ tahun & 0 & 0 \\
\hline & Total & 32 & 100 \\
\hline \multirow{4}{*}{2.} & Jenis Kelamin & & \\
\hline & Perempuan & 30 & 94 \\
\hline & Laki-laki & 2 & 6 \\
\hline & Total & 32 & 100 \\
\hline \multirow[t]{6}{*}{3.} & Pendidikan & & \\
\hline & D3/Sederajat & 20 & 62.5 \\
\hline & $\mathrm{S} 1$ & 7 & 22 \\
\hline & S1 Profesi & 4 & 12.5 \\
\hline & $\mathrm{S} 2$ & 1 & 3 \\
\hline & Total & 32 & 100 \\
\hline \multirow[t]{5}{*}{4.} & Pekerjaan & & \\
\hline & Apoteker & 5 & 16 \\
\hline & Tenaga Teknis & 10 & 31 \\
\hline & Perawat & 17 & 53 \\
\hline & Total & 32 & 100 \\
\hline \multirow[t]{5}{*}{5.} & Lama Kerja & & \\
\hline & $1-5$ tahun & 17 & 53 \\
\hline & $6-10$ tahun & 15 & 47 \\
\hline & $>10$ tahun & 0 & 0 \\
\hline & Total & 32 & 100 \\
\hline
\end{tabular}

Berdasarkan hasil yang didapat pada Tabel 3, diketahui bahwa mayoritas umur responden adalah 20 - 30 tahun sebanyak 22 responden (69\%), dengan mayoritas jenis 
kelamin responden adalah perempuan sebanyak 30 responden (94\%), dengan mayoritas pendidikan D3/Sederajat sebanyak 20 responden (62.5\%), dengan mayoritas pekerjaan perawat sebanyak 17 responden (53\%) dan lama bekerja terbanyak 1-5 tahun sebanyak 17 responden (53\%).

Tabel 4. Faktor Penyebab Dispensing Error

\begin{tabular}{|c|c|c|c|}
\hline $\begin{array}{c}\text { Faktor } \\
\text { Penyebab }\end{array}$ & Pernyataan & $\mathbf{N}$ & $\%$ \\
\hline \multirow[t]{5}{*}{ Komunikasi } & $\begin{array}{l}\text { Komunikasi apoteker } \\
\text { dan perawat dalam } \\
\text { penyiapan obat pasien } \\
\text { berlangsung baik }\end{array}$ & & \\
\hline & a. Sangat Setuju & 9 & 28 \\
\hline & b. Setuju & 17 & 53 \\
\hline & c. Kurang Setuju & 6 & 19 \\
\hline & d. Tidak Setuju & 0 & 0 \\
\hline \multirow{6}{*}{$\begin{array}{l}\text { Kondisi } \\
\text { lingkungan }\end{array}$} & Tersedia ruangan & & \\
\hline & $\begin{array}{l}\text { sendiri untuk } \\
\text { penyiapan obat }\end{array}$ & & \\
\hline & a. Sangat Setuju & 18 & 56 \\
\hline & b. Setuju & 9 & 28 \\
\hline & c. Kurang Setuju & 5 & 16 \\
\hline & d. Tidak Setuju & 0 & 0 \\
\hline \multirow{6}{*}{$\begin{array}{l}\text { Gangguan/ } \\
\text { interupsi } \\
\text { bekerja }\end{array}$} & $\begin{array}{l}\text { Tenaga kesehatan } \\
\text { merasa tidak terganggu }\end{array}$ & & \\
\hline & $\begin{array}{l}\text { dengan dering telepon } \\
\text { yang bunyi tiba-tiba }\end{array}$ & & \\
\hline & a. Sangat Setuju & 10 & 31 \\
\hline & b. Setuju & 9 & 28 \\
\hline & c. Kurang Setuju & 13 & 41 \\
\hline & d. Tidak Setuju & 0 & 0 \\
\hline \multirow[t]{5}{*}{$\begin{array}{l}\text { Beban } \\
\text { kerja }\end{array}$} & $\begin{array}{l}\text { Tenaga kesehatan } \\
\text { mampu menyelesaikan } \\
\text { sendiri setiap } \\
\text { pekerjaan }\end{array}$ & & \\
\hline & a. Sangat Setuju & 15 & 47 \\
\hline & b. Setuju & 9 & 28 \\
\hline & c. Kurang Setuju & 8 & 25 \\
\hline & d. Tidak Setuju & 0 & 0 \\
\hline Edukasi & $\begin{array}{l}\text { Penyiapan obat untuk } \\
\text { pasien sesuai dengan } \\
\text { permintaan pada resep }\end{array}$ & & \\
\hline
\end{tabular}

\begin{tabular}{lcc}
\hline a. Sangat Setuju & 18 & 56 \\
b. Setuju & 9 & 28 \\
c. Kurang Setuju & 5 & 16 \\
d. Tidak Setuju & 0 & 0 \\
\hline
\end{tabular}

Berdasarkan hasil kuesioner faktor penyebab ME fase dispensing pada Tabel 4 menunjukkan bahwa responden dalam penelitian ini mempersepsikan faktor gangguan/interupsi bekerja pada saat dispensing dapat menyebabkan $\mathrm{ME}$ dengan persentase terbesar untuk gangguan/interupsi bekerja yaitu $41 \%$ responden menyatakan kurang setuju dengan tenaga kesehatan merasa tidak terganggu dengan dering telepon yang bunyi tiba-tiba. Dering telepon dapat menganggu konsentrasi kerja yang dapat menyebabkan pekerja cenderung berbuat kesalahan dan akhirnya menurunkan produktivitas bekerja.

Beban kerja dapat menyebabkan ME pada fase dispensing. Dalam penyiapan obat, tenaga farmasi melakukan skrinning dan pengkajian resep, menyalin instruksi pemberian obat ke Kartu Pencatatan Obat (KPO), menginput obat dan membuat etiket obat dalam sistem, penyiapan obat untuk satu hari pemakaian, pengemasan obat, serah terima obat dan pengecekan oleh perawat yang kemudian disimpan pada kotak obat pasien. Perawat memainkan suatu peranan penting dalam sistem distribusi obat di rumah sakit dimana perawat menyiapkan dan merekonstitusi dosis untuk dikonsumsi, pemberian (pengonsumsian) obat, merekam tiap obat yang dikonsumsi serta memelihara persediaan obat di ruangan (Purba, 2013).

Hasil jawaban kuesioner terhadap beban kerja responden paling banyak menyatakan kurang setuju dengan tenaga kesehatan mampu menyelesaikan sendiri setiap pekerjaan. Tenaga farmasi dan tenaga perawat mengungkapkan 
jumlah pasien yang dirawat berpengaruh terhadap baik tidaknya penyiapan obat pasien. Dispensing error dapat terjadi karena jumlah petugas yang tidak memadai dan beban kerja yang berlebihan (Cahyono dan Suharjo, 2008).

Responden mempersepsikan komunikasi pada fase dispensing dapat menyebabkan ME, sebanyak $19 \%$ responden menyatakan kurang setuju dengan komunikasi apoteker dan perawat dalam penyiapan obat pasien berlangsung baik. Komunikasi dibutuhkan untuk mewujudkan kerja sama yang efektif, perawat bertanggung jawab untuk melakukan inerpretasi yang tepat terhadap order obat yang diberikan. Komunikasi yang kurang baik menyebabkan terjadinya misinterpretasi perawat dengan apoteker terhadap order obat yang harus diberikan kepada pasien (Rusmi et al., 2012).

Responden mempersepsikan kondisi lingkungan dapat menyebabkan ME dengan persentase jawaban responden sebesar 16\% dimana responden menyatakan kurang setuju dengan dengan tersedianya ruangan sendiri untuk penyiapan obat. Area dispensing harus didesain dengan tepat untuk menghindari kesalahan yang berkaitan dengan kondisi lingkungan. Dengan tidak adanya ruangan penyiapan obat/racikan kesalahan pada saat dispensing dapat terjadi (Depkes RI, 2008).

Adapun edukasi sebanyak $16 \%$ responden menyatakan kurang setuju dengan penyiapan obat untuk pasien sesuai permintaan pada resep karena pernah terjadi kesalahan pengambilan obat karena nama yang mirip. Kesalahan pada fase dispensing paling sering terjadi karena tulisan yang tidak jelas, atau karena tempat obat yang berdekatan, nama dan tampilan obat mirip (Bayang, 2013).

\section{PENUTUP}

\section{Kesimpulan}

1. Faktor penyebab ME fase prescribing meliputi gangguan bekerja yaitu terganggu dengan dering telepon, beban kerja yaitu tenaga kesehatan tidak mampu mengerjakan sendiri setiap pekerjaan, komunikasi yaitu kurang baiknya komunikasi lisan dokter dan apoteker tentang penggunaan obat untuk pasien, kondisi lingkungan yaitu pencahayaan yang kurang mendukung saat bekerja, dan edukasi yaitu penulisan resep yang tidak memenuhi syarat kelengkapan resep.

2. Faktor penyebab ME fase dispensing meliputi gangguan bekerja yaitu terganggu dengan dering telepon, komunikasi yaitu kurang baiknya komunikasi apoteker dan perawat dalam penyiapan obat pasien, beban kerja yaitu tenaga kesehatan tidak mampu menyelesaikan sendiri setiap pekerjaan, kondisi lingkungan yaitu tidak adanya ruangan penyiapan obat, dan edukasi yaitu penyiapan obat yang tidak sesuai permintaan resep.

\section{Saran}

1. Perlu diperhatikan kembali sistem pelayanan terutama dalam pelayanan pengobatan dan selalu mengutamakan kedisiplinan dalam bekerja serta selalu membangun komunikasi yang baik antara tenaga kesehatan.

2. Perlunya dilakukan penelitian lebih lanjut untuk mengetahui angka kejadian ME dan mengkaji lebih dalam tentang faktor penyebab ME serta mencari hubungan faktor tersebut terhadap kejadian ME.

\section{DAFTAR PUSTAKA}

Aronson, J.K. 2009. Medication errors: definitions and classification. $\mathrm{Br} \mathrm{J} \mathrm{Clin}$ Pharmacol. 6(67): 599-604. 
Bayang, A. T. 2013. Faktor Penyebab Medication Error di RSUD Anwar Makkatutu Kabupaten Bantaeng [tesis]. Fakultas Kesehatan Masyarakat Universitas Hassanuddin, Makassar.

Cahyono., dan Suharjo, B. 2008. Membangun Budaya Keselamatan Pasien dalam Praktik Kedokteran. Kanisius, Yogyakarta.

Departemen Kesehatan Republik Indonesia. 2008. Buku Saku Tanggung jawab Apoteker Terhadap Keselamatan Pasien (Patient Safety). Ditjen Bina Kefarmasian dan Alat Kesehatan Depkes RI, Jakarta.

Departemen Kesehatan Republik Indonesia. 2014. Peraturan Menteri Kesehatan Republik Indonesia Nomor 35 Tahun 2014 tentang Standar Pelayanan Kefarmasian di Apotek. Kemenkes RI, Jakarta.

Departemen Kesehatan Republik Indonesia. 2014. Peraturan Menteri Kesehatan Republik Indonesia Nomor 58 Tahun 2014 tentang Standar Pelayanan Kefarmasian di Rumah Sakit. Kemenkes RI, Jakarta.

Donsu, Y. C. 2016. Faktor Penyebab Medication Error Pada Pelayanan Kefarmasian Rawat Inap Bangsal Anak RSUP Prof. R. D. Kandou Manado [skripsi]. FMIPA Universitas Sam Ratulangi, Manado.

Hartayu, T. S., dan Widayati, A. 2005. Kajian Kelengkapan Resep Pediatri yang Berpotensi Menimbulkan Medication
Error di Rumah Sakit dan 10 Apotek di Yogyakarta. Universitas Sanata Dharma, Yogyakarta.

Ilyas, Y. 2011. Perencanaan SDM Rumah Sakit, Teori, Metoda dan Formula Cetakan Ketiga. Fakultas Kesehatan Masyarakat Universitas Indonesia, Depok.

Maiz, N., Nurmainah., dan Eka, K. U. 2014. Analisis Medication Error Fase Prescribing Pada Resep Pasien Anak Rawat Jalan di Instalasi Farmasi RSUD Sambas Tahun 2014. Jurnal Pharmascience. 1(1): 1-9.

Mansouri, A., Ahmadvand, A., Hadjibabaie, M., Javadi, M., and Khoee, S. H. 2014. A Review of Medication Errors in Iran: Sources, Underreporting Reasons and Preventive Measures. Iranian Journal of Pharmaceutical Research. 13(1): 6.

Nasution, R. F. H. 2009. Pengetahuan, Sikap dan Persepsi Petugas Gawat Darurat Terhadap Kesalahan Medik. Jurnal Kesehatan Masyarakat Nasional. 3(6): 270-274.

Purba, J. M. 2013. Komunikasi Dalam Keperawatan. USU digital library, Medan.

Rusmi, S. T., Indrianty, S., dan Allmin, M. 2012. Faktor Penyebab Medication Error di Instalasi Rawat Darurat. Jurnal Manajemen Pelayanan Kesehatan. 15(4): 182-187.

Soejono, C. H. 2008. Kerja Sama Antara Dokter dan Ahli Farmasi pada Layanan Informasi Kesehatan dalam Rangka 
Peningkatan Keselamatan Pasien.

Departemen Ilmu Penyakit Dalam RSCM, Jakarta.

Tarwaka, S. B. A dan Lilik, S. 2004. Ergonomi untuk Keselamatan, Kesehatan Kerja dan Produktivitas. UNIBA Press, Surakarta. 